\title{
Modelling of Effects of Cold Work on Sigma Phase Growth Rate in Super Duplex Stainless Steel
}

\author{
Takahiro OSUKI* and Kazuhiro OGAWA \\ Nippon Steel Corporation, 1-8 Fuso-cho, Amagasaki, Hyogo, Japan. \\ (Received on August 5, 2020; accepted on September 4, 2020)
}

\begin{abstract}
By the modelling of the precipitation and growth behaviour of the sigma phase the quantitative effects of amounts of cold work was investigated in super duplex stainless steels. The cold work promotes sigma phase precipitation. The equation to describe the growth rate of sigma phase proposed formerly by the authors was employed. That is based on the classical nucleation theory and J-M-A-K formula.

The effects of cold work was incorporated in that equation as two parameters. Those parameters were determined using the experimental data. Experimental data was obtained by measuring the growth of sigma phase in the isothermally heated specimen at 1173 and $1223 \mathrm{~K}$. The specimens consisting of 25 mass $\%$ Cr-mass $7 \% \mathrm{Ni}-3$ mass $\%$ Mo-2mass $\% W-0.3 m a s s \% N$ super duplex stainless steel were prepared with various reduction levels of 3 to $10 \%$ in cold rolling process. As result the model to described quantitatively the effect of the amount of cold work on the acceleration of sigma phase was proposed. The validity of the model was confirmed by clarifying to have good fit to the experimental data referred from another work published.
\end{abstract}

KEY WORDS: duplex stainless steel; sigma phase; modelling; cold work; growth rate; kinetics.

\section{Introduction}

Duplex stainless steels are widely applied to the various structures because they exhibit high cost performance. These steels have the potential to obtain a high corrosion resistance, high strength and high toughness economically because they have lower nickel content in comparison with that in austenitic stainless steels. In later years, super duplex stainless steels improved in terms of corrosion resistance due to the increase in the amount of chromium, molybdenum, tungsten ${ }^{1-4)}$ and nitrogen have been developed. The increase in the amount of these elements promotes the harmful intermetallic such as sigma phase. Therefore the prevention of this phase formation is an important subject in the welding, fabrication, and manufacturing process.

Many research works have focused on sigma phase precipitation in duplex stainless steel applicable to the heat treatment, hot work or welding process. In many research works focusing on the precipitation kinetics of the sigma phase, the growth properties were determined by using an experimental method and in steels of various chemistries. $^{5-18)}$

It is well known that sigma phase precipitation is accelerated in cold worked steel duplex stainless steel. ${ }^{19)}$ Time-temperature-precipitation (TTP) curve of sigma phase

\footnotetext{
* Corresponding author: E-mail: osuki.65m.takahiro@jp.nipponsteel.com
}

is shifted to the direction of shorter time in duplex stainless steels consisting of various chemical compositions. However it is not easy to extend those findings to any other duplex stainless steel in the different chemical composition. Regarding the solution treated steels the authors have proposed the model to describe the effect of alloying elements such as chromium or molybdenum on the growth of sigma phase in previous works. ${ }^{20-22)}$ In this paper as the first step to proposal of quantitative prediction way of the TTP curve of sigma phase precipitation in cold worked steels the modelling of effects of cold work on sigma phase growth rate and TTP curve in super duplex stainless steel was investigated using the model proposed in previous works. ${ }^{21,22)}$

\section{Experimental}

Duplex stainless steel of UNS S39274 shown in Table 1 were melt with a laboratory electric furnace. Those steels were fabricated to the $15 \mathrm{~mm}$ thick plates by hot forging and hot rolling followed by solution treatment. Solution treatment is performed at $1323 \mathrm{~K}$ for $1800 \mathrm{~s}$ and quenched by

Table 1. Chemical compositions of steels tested (mass\%).

\begin{tabular}{cccccccccc}
\hline $\mathrm{C}$ & $\mathrm{Si}$ & $\mathrm{Mn}$ & $\mathrm{P}$ & $\mathrm{S}$ & $\mathrm{Ni}$ & $\mathrm{Cr}$ & $\mathrm{Mo}$ & $\mathrm{W}$ & $\mathrm{N}$ \\
\hline 0.02 & 0.16 & 0.50 & 0.019 & 0.001 & 7.13 & 25.34 & 3.05 & 2.03 & 0.316
\end{tabular}




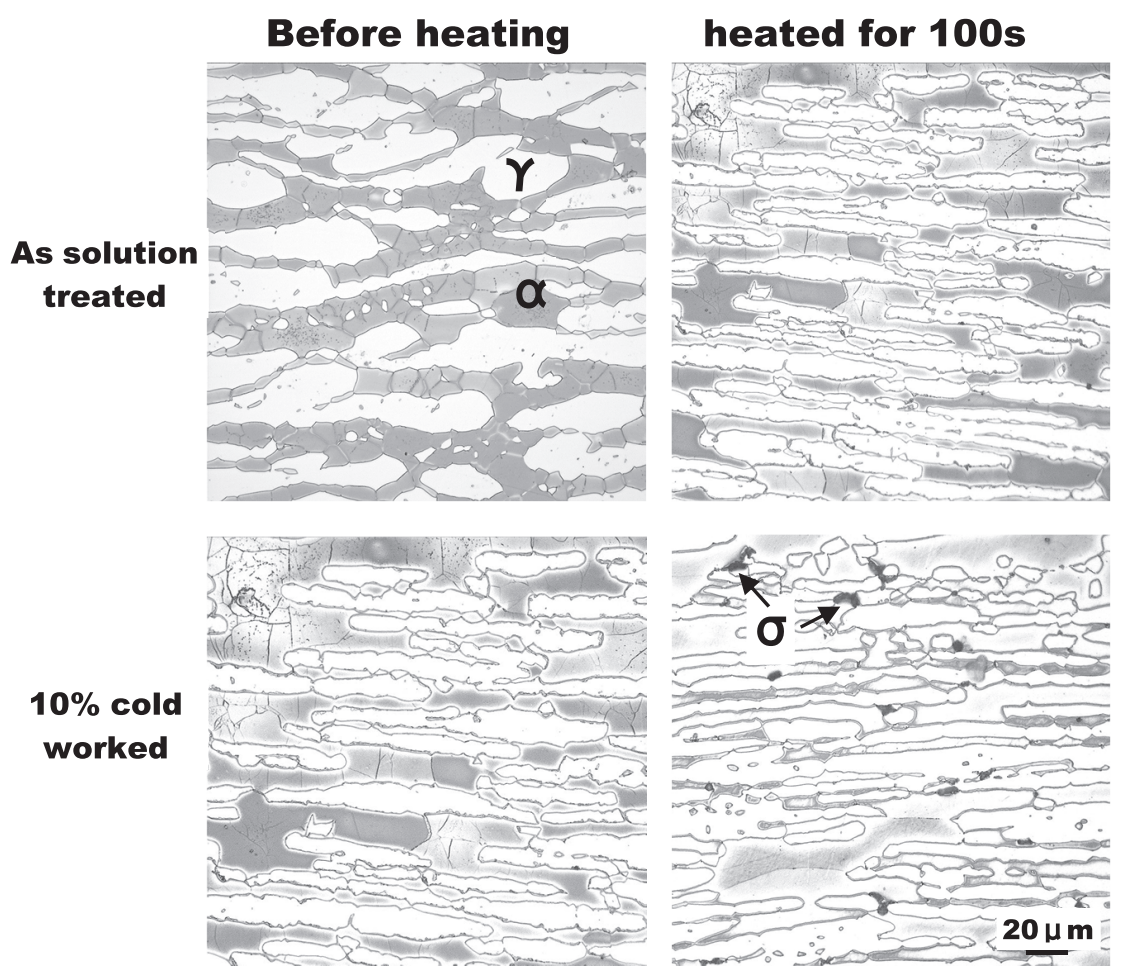

Fig. 1. Examples of sigma phase growth heated at $1173 \mathrm{~K}$ in $10 \%$ cold worked steel and in as solution treated steel of 25 mass $\%$ Cr-7mass $\% \mathrm{Ni}-3$ mass $\%$ Mo- 2 mas $\% W-0.3$ mass $\% \mathrm{~N}$.

water. The plates were cold worked with various reduction of $3 \%, 6 \%, 10 \%$ in thickness. Employing those plates the specimens were machined to be $11 \mathrm{~mm}$ thick, $11 \mathrm{~mm}$ wide and $60 \mathrm{~mm}$ long and heated at various constant temperatures at $1173 \mathrm{~K}$ or $1273 \mathrm{~K}$ during various time followed by quenching with helium gas. In addition the long term heating for $360 \mathrm{ks}$ at each temperature same as the above tests in order to the equilibrium fraction of sigma phase. After the heat treatment the specimens were polished and electrochemically etched in $10 \%$ oxalic acid and $10 \mathrm{~N} \mathrm{KOH}$ aqueous solution in cross section for microstructure observation. As an example Fig. 1 shows the optical microstructure of cold worked $25 \% \mathrm{Cr}-7 \% \mathrm{Ni}-3 \% \mathrm{Mo}-2 \% \mathrm{~W}-0.3 \% \mathrm{~N}$ steel heated at $1173 \mathrm{~K}$ for $1000 \mathrm{~s}$. Area fraction of sigma phase etched as black phase was measured with an image analyser. In this work all the \% regarding chemical compositions mean mass $\%$.

\section{Application of Kinetic Model to Cold Worked Steel}

The incorporation of effect of cold work in growth model in the present theoretical model was investigated. It has been clarified in the previous work $^{21,22)}$ that the growth of the sigma phase in the early stage in duplex stainless steels is according to the following equations based on the traditional nucleation theory. ${ }^{23)}$ The parameter $\mathrm{X}$, which is the ratio of the fraction of transformed phase to that in the equilibrium, is given as the following equation. In Eq. (1) t is heating time and $\mathrm{m}$ is the degree in the J-M-A-K law. ${ }^{23)}$

$$
\mathrm{X}=1-\exp \left[-\left(k_{p} \cdot t\right)^{m}\right]
$$

The growth rate constant $k_{p}$ in Eq. (1) has been proposed as the following by the authors in the previous work. ${ }^{21,22)}$

$$
\begin{array}{r}
k_{p}=K_{00}\left(T_{e q} / \Delta T\right)^{4 / 5} D_{\text {eff }} \exp \left[-\phi\left(T_{e q} / \Delta T\right)^{2} / R T\right] \\
\phi=\frac{32 \pi}{15} V^{2} N \sigma^{3} /\left(C_{p} \Delta H\right)^{2} \ldots \ldots \ldots \ldots \ldots \ldots \ldots \ldots \ldots \ldots \ldots
\end{array}
$$

Here the parameter of $K_{00}$ is expressed as the following form the previous work. ${ }^{20)} \mathrm{R}$ is gas constant and $\mathrm{N}$ is Avogadro's number.

$$
K_{00}=\left[16 \sqrt{2} \cdot \frac{\pi^{2}}{15} \cdot V C_{0} N_{x} \omega_{0}{ }^{1 / 2} \sigma^{2} /\left(C_{p} \Delta H\right)^{2} / r_{a}{ }^{4}\right]^{2 / 5} \ldots
$$

The parameter of $r_{a}$ is the lattice constant and $\omega_{0}$ is super saturation defined as the same as the previous work ${ }^{20)}$

$$
=\left[\frac{\sqrt{2 \pi}}{2} C_{0} N_{x} \omega_{0}{ }^{1 / 2} \phi /\left(V N \sigma r_{a}{ }^{4}\right)\right]^{2 / 5}
$$

Here the parameter of $\mathrm{N}_{\mathrm{x}}$ is number of atoms to determine the growth rate, $\mathrm{V}$ is the molar volume, $\sigma$ is the interface energy between sigma and ferrite phase, $D_{\text {eff }}$ is the effective diffusion constant ${ }^{20}$ of the dominant atom, $\Delta \mathrm{H}$ is the enthalpy of transformation of intermetallic, $\mathrm{T}_{\mathrm{eq}}$ is the solvus temperature of the intermetallic phase, $\Delta \mathrm{T}$ is the amount of undercooling $\left(=\mathrm{T}_{\mathrm{eq}}-\mathrm{T}\right)$, and $\mathrm{C}_{\mathrm{p}}$ is the concentration of the dominant atom to determine the growth rate in the intermetallic phase and $\mathrm{C}_{\mathrm{o}}$ is concentration of the dominant atom to determine the growth rate in the steel.

In the cold worked duplex stainless steels the dislocation density can increase, so that the diffusion constant $D_{\text {eff }}$ and the enthalpy of transformation of intermetallic $\Delta \mathrm{H}$ can be influenced by cold work. Those two influence factors of cold work were incorporated in the growth rate constant $\mathrm{k}_{\mathrm{p}}$ by applying the parameters of $\lambda_{1}$ and $\lambda_{2}$ as the function of 
the amount of cold work.

$$
k_{p, c w}=\lambda_{1} K_{00}\left(T_{e q} / \Delta T\right)^{4 / 5} D_{e f f} \exp \left[-\lambda_{2} \phi\left(T_{e q} / \Delta T\right)^{2} / R T\right]
$$

, where the values of $\lambda_{1}$ and $\lambda_{2}$ equal to 1 in the solution treated steel without cold work.

Quantitative modelling of effects of cold work on sigma phase growth is achieved by determining of the parameters incorporated as the function of the amount of cold work. The growth rate constant $\mathrm{k}_{\mathrm{p}}$ is the function of temperature and determined by the four parameters of $\mathrm{D}_{\text {eff }}, \mathrm{T}_{\mathrm{eq}}, \varnothing$ and $K_{00}$. Two parameters $D_{\text {eff }}$ and $T_{\text {eq }}$ of four are given by the thermodynamics data base. So that by the following experiment the rests of two parameters $\varnothing$ and $K_{00}$ were determined. The unknown parameters of $\lambda_{1}$ and $\lambda_{2}$ are determined by applying the experimental value of $\mathrm{k}_{\mathrm{p}}$ at least at some two reference temperatures of $T_{r 1}$ and $T_{r 2}$ to the following equations.

$$
\begin{aligned}
& k_{p, c w}\left(T_{r 1}\right)=\lambda_{1} K_{00}\left(T_{e q} / \Delta T_{r 1}\right)^{4 / 5} D_{e f f} \exp \\
& {\left[-\lambda_{2} \phi\left(T_{e q} / \Delta T_{r 1}\right)^{2} / R T_{r 1}\right]} \\
& k_{p, c w}\left(T_{r 2}\right)=\lambda_{1} K_{00}\left(T_{e q} / \Delta T_{r 2}\right)^{4 / 5} D_{e f f} \exp \\
& {\left[-\lambda_{2} \phi\left(T_{e q} / \Delta T_{r 2}\right)^{2} / R T_{r 2}\right]}
\end{aligned}
$$

\section{Application of Model to Experimental Data}

\subsection{Sigma Phase Growth in Cold Worked Specimens}

Figure 1 shows the examples of microstructure in cold worked specimens heated at $1173 \mathrm{~K}$ for the durations of $100 \mathrm{~s}$. In these micrographs the sigma phase is observed as black phase. The larger fraction of sigma phase was formed in the cold rolled specimen with $10 \%$ reduction. The black etched area fraction of sigma phase was measured with the image analyser ${ }^{21)}$ using the specimens heated at the constant temperature for the various durations.

\subsection{Determination of Parameters by Experiment}

To clarify the applicability of Eq. (1) to the cold worked steels, the progress of transformation as the form of $\log (-\log (1-X))$ were plotted against the heating time as shown in Figs. 2 and 3. From the results it was found that the sigma phase grew according to the J-M-A-K ${ }^{23)}$ Eq. (1) with the value of $\mathrm{m}$ as 2.5 . The growth rate constants $k_{p, c w}$ obtained from those results. Using the values of $k_{p, c w}$ at the two reference temperatures of $1173 \mathrm{~K}$ and $1223 \mathrm{~K}$ the parameters of $\lambda_{1}$ and $\lambda_{2}$ were obtained as shown in Table 2. The experimental values of $k_{p, c w}$ were plotted against the temperature together with the calculated curves as shown Fig. 4. The calculated curves are produced applying the parameters to Eq. (6) based on the model proposed in the previous work. ${ }^{21)}$ The calculated curves sufficiently agreed with the experimental data. The relation between the parameters of $\lambda_{1}$ and $\lambda_{2}$ and the amount of cold work are shown in Fig. 5. Both parameters increased proportionally to the amount of cold work $\mathrm{CW}(\%)$ and the following experimental formula for engineering use to estimate the influence of cold work were obtained.

$$
\lambda_{1}=1+0.35 \mathrm{CW}(\%)
$$

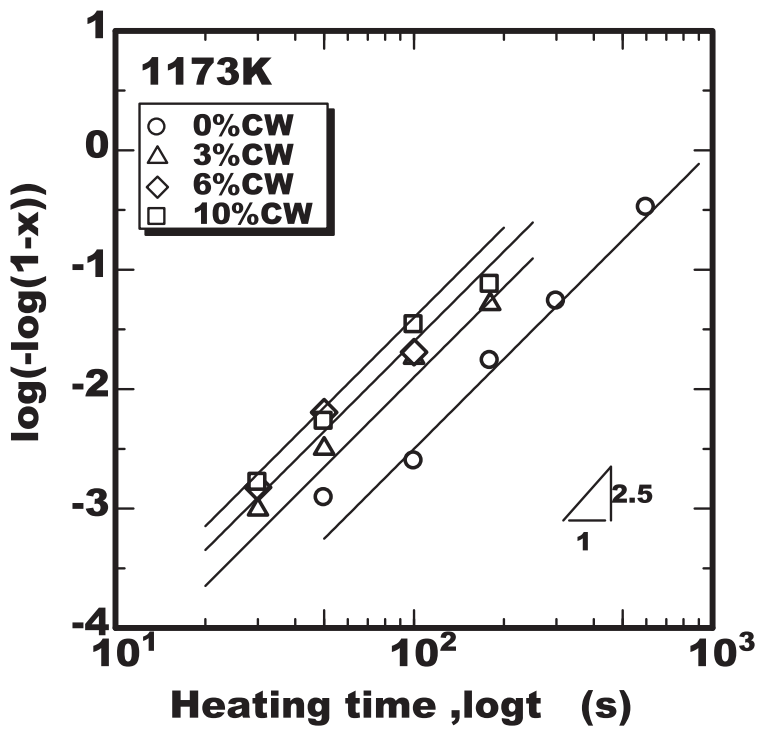

Fig. 2. Sigma phase growth during isothermal heating at $1173 \mathrm{~K}$ in steels with various reduction level in cold rolling.

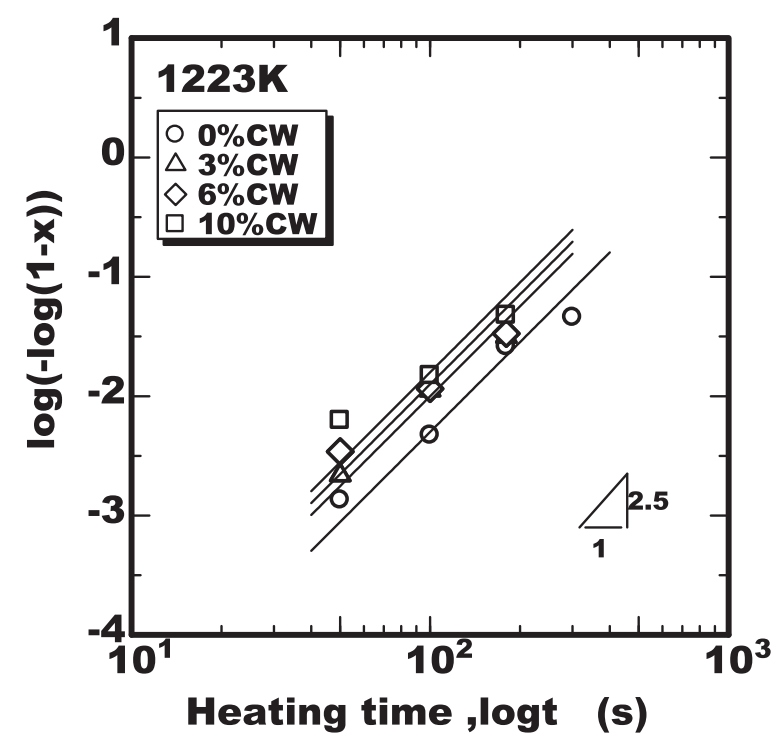

Fig. 3. Sigma phase growth during isothermal heating at $1223 \mathrm{~K}$ in steels with various reduction level in cold rolling.

Table 2. Values of parameters $\lambda_{1}$ and $\lambda_{2}$ for precipitation model proposed in cold worked steels obtained by experiment.

\begin{tabular}{cccccc}
\hline $\mathrm{CW}(\%)$ & $\mathrm{T}_{\mathrm{eq}}(\mathrm{K})$ & $\phi$ & $\mathrm{K}_{00}\left(\mathrm{~s}^{-1}\right)$ & $\lambda_{1}$ & $\lambda_{2}$ \\
\hline 0 & 1339 & 200 & $2.8 \times 10^{11}$ & 1 & 1 \\
3 & 1339 & 200 & $2.8 \times 10^{11}$ & 1.9 & 1.1 \\
6 & 1339 & 200 & $2.8 \times 10^{11}$ & 3.5 & 1.3 \\
10 & 1339 & 200 & $2.8 \times 10^{11}$ & 4.3 & 1.4 \\
\hline
\end{tabular}

$$
\lambda_{2}=1+0.042 \mathrm{CW}(\%)
$$

\subsection{Extension to TTP-curve}

TTP curve is understood to be a kind of contour line of the each progress of precipitation. The time $t_{c}$ to each fraction ratio of precipitation $\mathrm{X}_{0}$ is calculated by the Eq. (9) obtained from the above Eqs. (1) and (6). 
25Cr-7Ni-3Mo-2W-0.3N

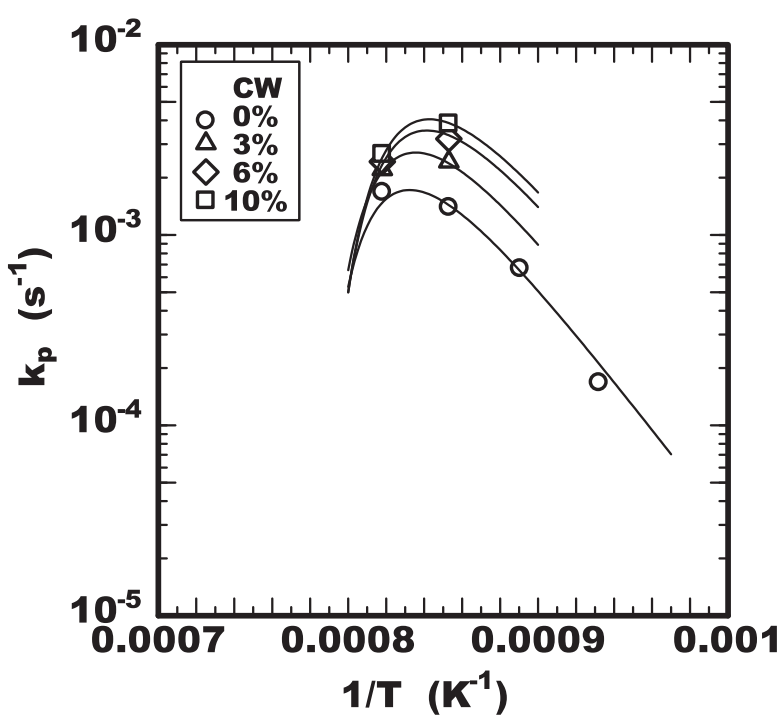

Fig. 4. Effect of heating temperature on sigma phase growth rate constant in various cold worked steels.
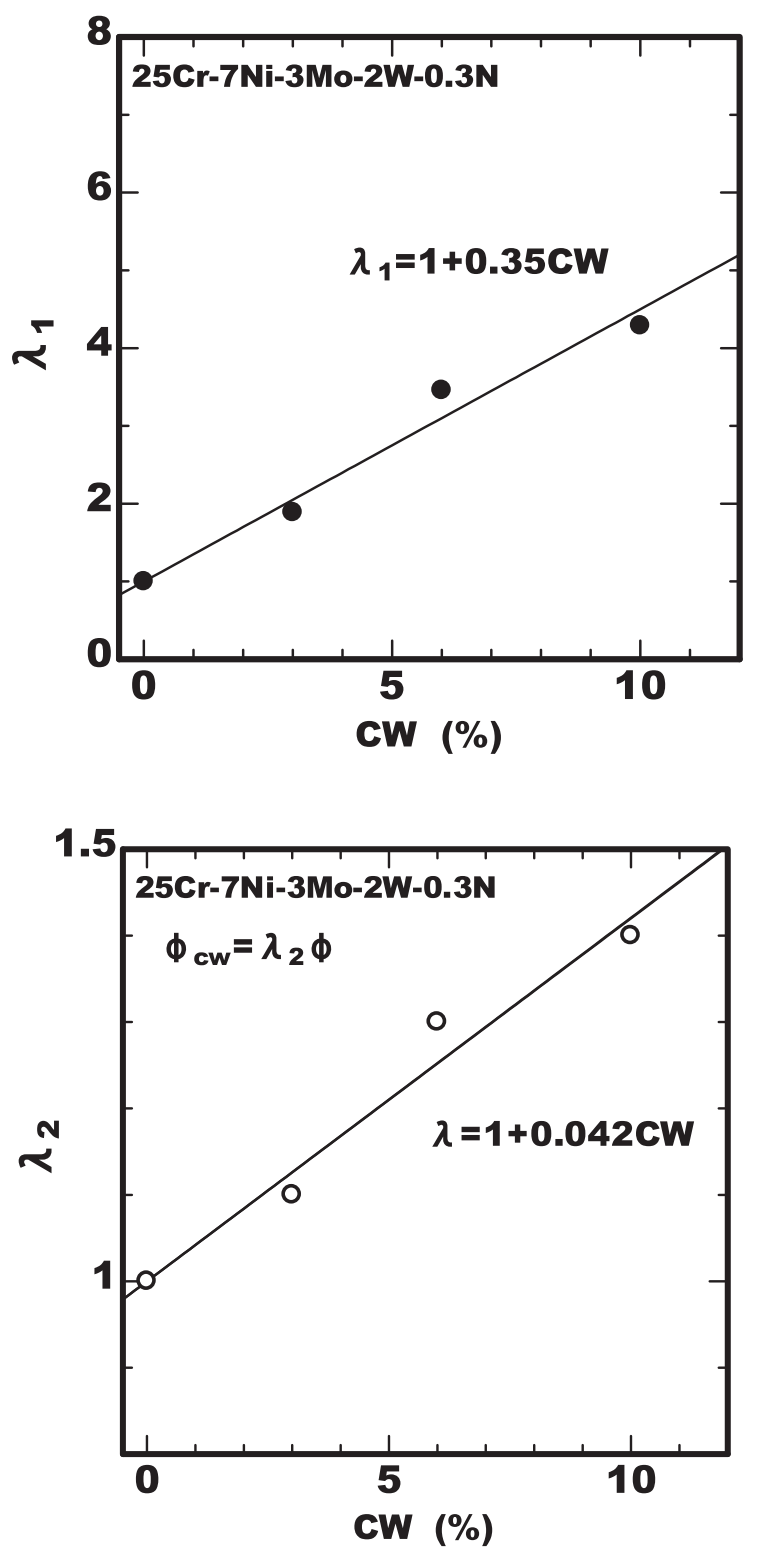

Fig. 5. Coefficients $\lambda_{1}$ and $\lambda_{2}$ to apply parameters $\varphi$ and K00 to cold worked steels.

$$
\begin{aligned}
& t_{c}=\left(\lambda_{1} K_{00}\right)^{-1}\left[-\ln \left(1-X_{0}\right)\right]^{0.4}\left(T_{e q} / \Delta T\right)^{-0.8} / \\
& D_{e f f} \exp \left[\lambda_{2} \phi\left(T_{e q} / \Delta T\right)^{2} / R T\right]
\end{aligned}
$$

TTP curves for $\mathrm{X}_{0}$ of $0.5 \%$ and $1.5 \%$ are drawn using this equation together with the experimental results with the volume fraction of $1 \%$ as the criteria as shown in Figs. 6 to 9. The curves obtained had approximately good fit to the experimental results shown as plotted data.

The temperature and the time at the nose of TTP curve are obtained as the solution when the value of $\partial \mathrm{t} / \partial \mathrm{T}$ of $\mathrm{Eq}$. (9) equals to 0 . The effect of the amount of cold work on the nose time of TTP curve predicted is shown in Fig. 10. The nose time with the criteria of $1 \%$ in sigma phase fraction in

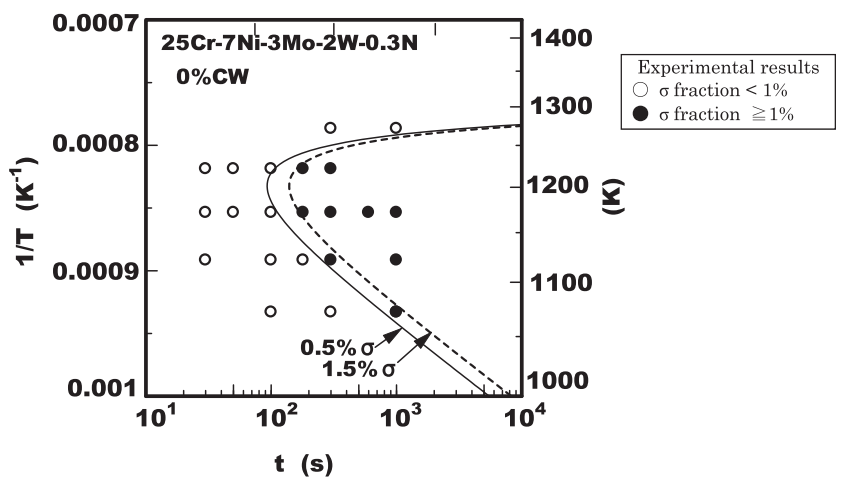

Fig. 6. Comparison of C-curve calculated by physical model and experimental results in as solution treated without cold work steel.

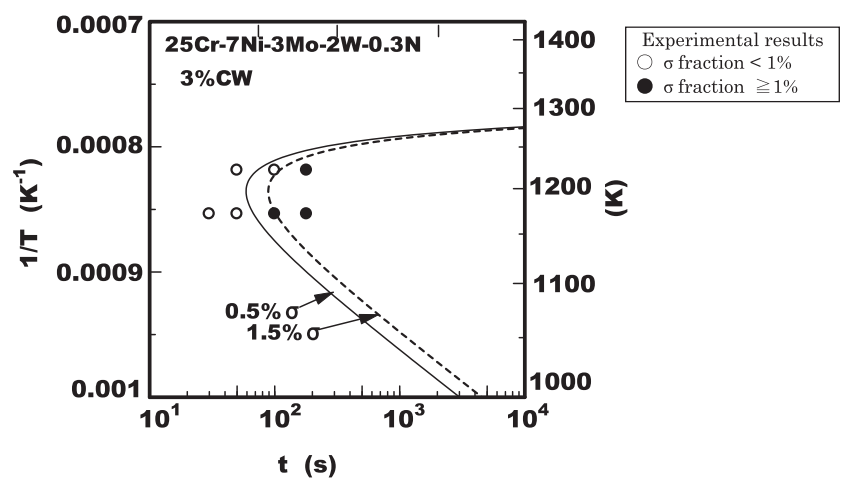

Fig. 7. Comparison of C-curve calculated by physical model and experimental results in $3 \%$ cold worked steel.

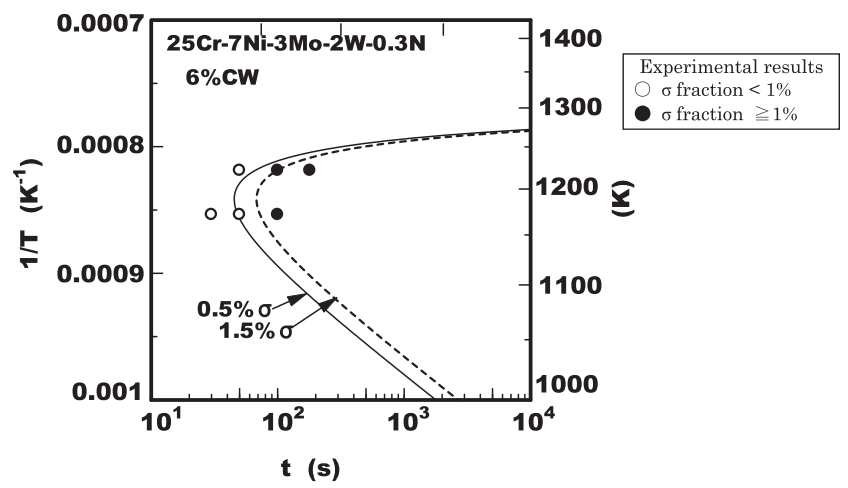

Fig. 8. Comparison of C-curve calculated by physical model and experimental results in $6 \%$ cold worked steel. 


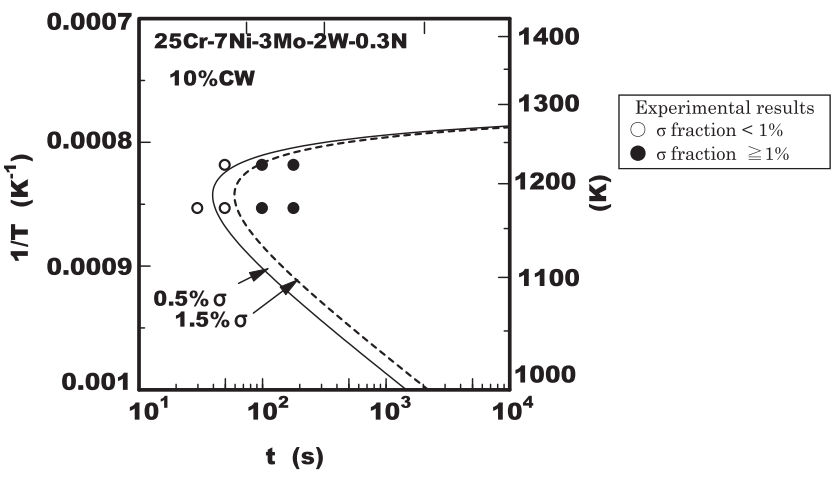

Fig. 9. Comparison of C-curve calculated by physical model and experimental results in $10 \%$ cold worked steel.
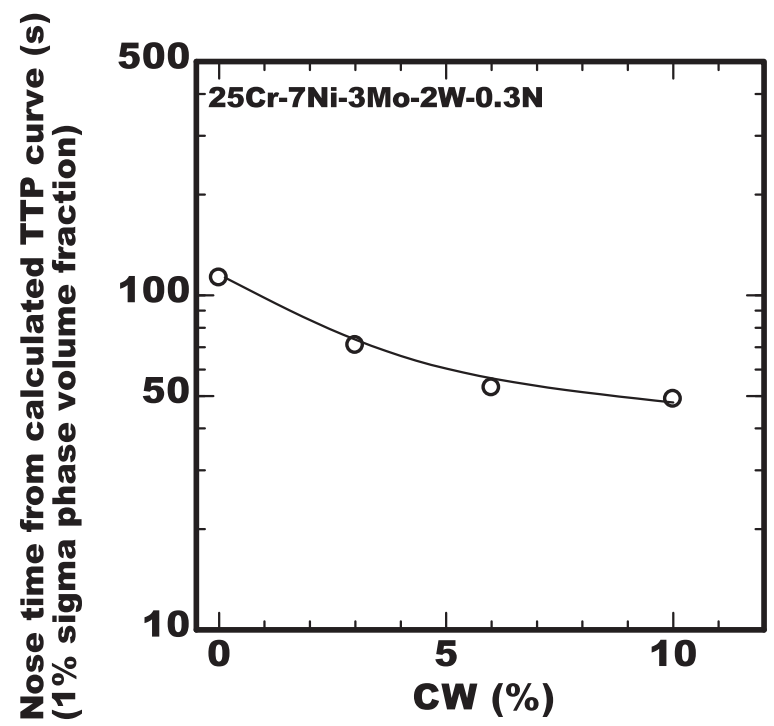

Fig. 10. Effect of amount of cold work on nose time of $1 \%$ sigma phase fraction.

the $6 \%$ cold worked steel can be approximately half of that in as solution treated steel.

\section{Discussion}

The physical meaning of effect of cold work on the parameters of $\lambda_{1}, \lambda_{2}$ is investigated. Dislocation density is increased by cold working. As results the number of nucleation sites and vacancy density are increased. The parameter of $\lambda_{1}$ is considered as consisting of the product of the parameters of $\lambda_{1 a}$ and $\lambda_{1 b}$. The parameter $\lambda_{1 a}$ regards the increase of number of nucleation sites $N_{x}$ resulting in $\lambda_{1 a} \mathrm{~N}_{x}$ in Eq. (4) and the parameter $\lambda_{1 b}$ regards the increase of vacancy to accelerate the diffusion of atoms. The diffusion of dominant atom of alloying elements such as chromium is driven by exchanging positions in the lattice between the atoms and the vacancies. Therefore the increase of vacancy by cold working accelerates the diffusion of atoms due to the increase of diffusion path. As results It is understood the parameter of $\lambda_{1}$ means the proportional coefficient which reflects the increase of dislocation with the increase of the amount of cold work. However the effect of acceleration of diffusion by dislocation can be reduced in the higher temperature. The parameter of $\lambda_{2}$ is considered to play the role to reduce the excessive acceleration effect with the elevation

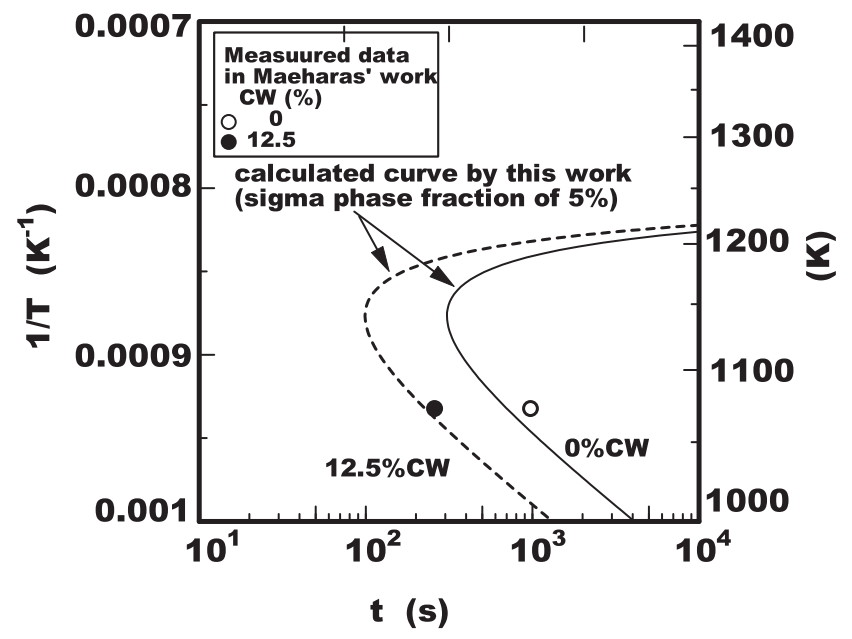

Fig. 11. Comparison calculated curve of 5\% sigma phase fraction by this work's model and measured data in other work in 25 mass $\% \mathrm{Cr}-7$ mass $\% \mathrm{Ni}-3$ mass $\% \mathrm{Mo}-0.2$ mass $\% \mathrm{~N}$ steel.

of temperature as described in the following.

While the driving force for nucleation of intermetallic phase $\Delta \mathrm{G}$ corresponds to $C_{p} \Delta H \Delta \mathrm{T} / T_{e q}{ }^{23)}$ the growth rate constant in the cord worked steel is written as the following in the basis of Eqs. (3) and (6).

$$
\begin{aligned}
& k_{p, c w}=\lambda_{1} K_{00}\left(T_{e q} / \Delta T\right)^{4 / 5} D_{e f f} \exp \\
& {\left[-\lambda_{2} \frac{32 \pi}{15} V^{2} N \sigma^{3} /(\Delta G)^{2} / R T\right]}
\end{aligned}
$$

When the driving force is as $\Delta G_{c w}$ in the cold worked steel,

$$
\begin{gathered}
k_{p, c w}=\lambda_{1} K_{00}\left(T_{e q} / \Delta T\right)^{4 / 5} D_{\text {eff }} \exp \\
{\left[-\frac{32 \pi}{15} V^{2} N \sigma^{3} /\left(\Delta G_{c w}\right)^{2} / R T\right]} \\
\Delta G_{c w}=\Delta \mathrm{G} / \sqrt{\lambda_{2}} \ldots \ldots \ldots \ldots . . . .
\end{gathered}
$$

From the above equation the parameter of $\lambda_{2}$ has the effect to reduce the driving force of nucleation. As results that contributes to reducing the excessive acceleration by the increase of dislocation in the higher temperature range. Because the effect of the term of

$$
\exp \left[-\frac{32 \pi}{15} V^{2} N \sigma^{3} /\left(\Delta G_{c w}\right)^{2} / R T\right]
$$

on the value of $k_{p, c w}$ is the less in the higher temperature range.

To clarifying validity and extendability of this model proposed, the applicability to the data obtained in another work ${ }^{19)}$ was investigated. The data were extracted from the Maeharas' work ${ }^{19)}$ published in TETSU-to-HAGANE. That work has shown the experimental data regarding the growth properties of sigma phase in cold worked steels with the reduction of $12.5 \%$ by cold rolling. Those have been obtained using the steel corresponding to SUS329J4L and by measuring fractions of sigma phase after heated at $1073 \mathrm{~K}$ for various duration. For the reference the time to the fraction of $5 \%$ of sigma phase were extracted from the experimental data. ${ }^{19)}$ The TTP curves of 5\% sigma phase fraction of SUS329J4L 
steel as solution treated was calculated applying the value of parameters of $\mathrm{T}_{\mathrm{eq}}, \mathrm{K}_{00}$ and $\phi$ of $25 \mathrm{Cr}-7 \mathrm{Ni}-3 \mathrm{Mo}-0.3 \mathrm{~N}$ steel shown in previous work ${ }^{21)}$ to Eq. (11). The TTP curves of $5 \%$ sigma phase fraction in cold worked steel was calculated using Eq. (11) after calculating the parameter of $\lambda_{1}$ and $\lambda_{2}$ by applying the value of CW of $12.5 \%$ to Eqs. (9) and (10). The results are shown in Fig. 11, where the referred experimental data were plotted together. The experimental data plotted from in another work had good fit to the calculated TTP curve at $1073 \mathrm{~K}$. From the results the validity and extendability of this model proposed to another duplex stainless steel consisting of different chemical composition was confirmed.

\section{Conclusion}

The following conclusions were obtained from the investigation regarding the sigma phase precipitation in cold worked duplex stainless steels.

(1) The sigma phase precipitation is accelerated by the increase in the amount of cold work.

(2) It was confirmed the sigma phase in the cold worked steel in the early stage of precipitation grows according to the kinetic model based on the classical nucleation theory proposed.

(3) The physical model was proposed to describe quantitatively the acceleration effect of cold working on the sigma phase precipitation as a function of the amount of cold work.

(4) The validity of the model proposed was confirmed by good fit to the experimental data of the duplex stainless steel consisting of different chemical composition referred from another work published.

\section{REFERENCES}

1) K. Ogawa, H. Okamoto, M. Ueda, M. Igarashi, T. Mori and T. Kobayashi: Weld. Int., 10 (1996), 466.

2) K. Ogawa, H. Okamoto, M. Igarashi, M. Ueda, T. Mori and T. Kobayashi: Weld. Int., 11 (1997), 14
3) E. B. Haugan, M. Næss, C. T. Rodriguez, R. Johnsen and M. Iannuzzi: Corrosion, 73 (2017), 53.

4) H. Okamoto: Proc. Applications of Stainless Steel '92, (Stockholm), Stainless Steel World, Netherland, (1992), 360.

5) P. Ferro and F. Bonollo: Metall. Mater. Trans. A, 43 (2012), 1109.

6) H. Sieurin and R. Sandstrom: Mater. Sci. Eng. A, 444 (2007), 271.

7) A. P. Miodownik and N. Saunders: Mater. Sci. Technol., 18 (2002), 861.

8) J. O. Nilsson, P. Kangas, A. Wilson and T. Karlsson: Metall. Mater. Trans. A, 31 (2000), 35.

9) J. W. Elmer, T. A. Palmer and E. D. Specht: Metall. Mater. Trans. A, 38 (2007), 464.

10) S. Wessman, L. Karlsson, R. Pettersson and A. Östberg: Weld. World, 56 (2012), No. 11-12, 79.

11) K. Nishimoto, K. Saida and O. Katsuyama: Weld. World, 50 (2006), No. 3-4, 13.

12) J. O. Nilsson, T. Huhtala, P. Jonsson, L. Karlsson and A. Wilson: Metall. Mater. Trans. A, 27 (1996), 2196.

13) S. Hertzman, T. Huhtala, L. Karlsson, J. O. Nilsson, M. Nilsson, R. Jargelius-Pettersson and A. Wilson: Mater. Sci. Technol., 13 (1997), 604.

14) S. Hertzman, R. Pettersson, K. Frisk and T. Jerwin: Proc. 6th World Duplex Conf., (Venice), Associazione Italiana di Metallurgia, Milano, (2000), 347.

15) K. Kondo, M. Ueda, K. Ogawa, H. Okamoto and M. Igarashi: Proc. Innovation Stainless Steel, (Florence), Associazione Italiana di Metallurgia, Milano, (1993), 2191.

16) Y. H. Lee, K. T. Kim, Y. D. Lee and K. Y. Kim: Mater. Sci. Technol., 14 (1998), 757.

17) Y. S. Ahn and J. P. Kang: Mater. Sci. Technol., 16 (2000), 382.

18) Y. Maehara, M. Koike, N. Fujino and T. Kunitake: Trans. Iron Steel Inst. Jpn., 23 (1983), 240.

19) Y. Maehara, N. Fujino and T. Kunitake: Tetsu-to-Hagané, 68 (1982), 673 (in Japanese).

20) K. Ogawa and T. Osuki: Q. J. Jpn. Weld. Soc., 33 (2015), 55 (in Japanese).

21) K. Ogawa and T. Osuki: ISIJ Int., 59 (2019), 122.

22) K. Ogawa and T. Osuki: ISIJ Int., 59 (2019), 129.

23) T Nishizawa: Thermodynamics of Microstructures, ASM International, Materials Park, OH, (2008), 91.

24) Y. Shimada, M. Hatakeyama, J. Hirabayashi, Y. Yamamoto, K. Sato and S. Sunada: Mater. Trans., 60 (2019), No. 11, 2378.

25) I. F. Machao and A. F. Padilha: ISIJ Int., 40 (2000), 719

26) Y. Shimoide, J. Cui, C.-Y. Kang and K. Miyahara: ISIJ Int., 39 (1999), 191.

27) W. Reick, M. 1. Pohl and A. F. Padilha: ISIJ Int., 38 (1998), 567.

28) S.-C. Kim, Z. Zhang, Y. Furuya, C.-Y. Kang, J.-H. Sung, Q.-Q. Ni, Y. Watanabe and I.-S. Kim: Mater. Trans., 46 (2005), 1656.

29) S.-H. Jeon, I.-J. Park, H.-J. Kim, S.-T. Kim, Y.-K. Lee and Y.-S. Park: Mater. Trans., 55 (2014), 971.

30) K. Ogawa and T. Osuki: ISIJ Int., 60 (2020), 1016.

31) S.-H. Jeon, S.-T. Kim, S.-Y. Kim, M.-S. Choi and Y.-S. Park: Mater. Trans., 54 (2013), 1473. 